\title{
Researching Gender Professions: Nurses as Professionals
}

\author{
Benjamin Zufiaurre ${ }^{1, *}$ \& Maider Pérez de Villarreal ${ }^{1}$ \\ ${ }^{1}$ School of Education. Public University of Navarra. Pamplona 31006 (Navarra), Spain \\ *Correspondence: School of Education. Public University of Navarra. Pamplona 31006 (Navarra), Spain. E-mail: \\ zufiaurre@unavarra.es
}

Received: April 25, 2018

Accepted: May 17, 2018 Online Published: May 23, 2018

doi:10.5430/jct.v7n1p197

URL: https://doi.org/10.5430/jct.v7n1p197

\begin{abstract}
Nurses as professionals of health, childhood education teachers, social workers and caregivers, join a group of "feminine professions" which grew through policies of a welfare state in postwar constructive period, or in times of postwar accords (Jones, 1983). These professions are under challenge because of neoliberal policies and practices in the 21 st century. In the paper, we want to give lights to the contradictory situations nurses face, as workers and as care keepers. Nurses, suffer of a combination of public and private functions, at work, at home, and when caring family relatives. The way women feel about their role as professionals, and as women and workers, is illuminative, as we enquired in a funded research developed with nurses in the community of Navarra, Spain, first from 1993 to 1996, and next, checking a continuity each ten years, 2006 and next 2016.
\end{abstract}

Keywords: feminine professions, health professionals, nurses, stereotypes, sexism

\section{Introduction: Feminism Socially Biased}

Campaigns as "MeToo", are dealing about the differences between men and women, to say: lower wages, unequal distribution of responsibilities, devalued professional identities, sexual differences, sexual harassment, and others. "Gender", as an issue has spread to all areas of life and of research, in the twenty first century. But we have missed the chance to create a discipline that welcomes practitioners and academics, practice and theory, inclusion and permeability, consciousness and action (Weiner, 2012: p.3). Gender studies have become too theoretical, while research on the dynamism of practices is left aside. Moreover, what this means, is that, while feminist thinking has spread out for overall democratic growing, feminist activism, has taken a back seat.

But certainly, since the beginnings of patriarchal societies, women have run a long journey to think and communicate their freedom as human's in a society where the male had, and still have, the last word. To be a woman today, can be a terrible obligation to get on. Some can do it very well. But not all are able to overcome the historical deficits being carried, and feminist critique, should understand that the same structures of power, which are, or can be, used for emancipation, limit women as subject for "feminism" (Despentes, 2017). In the fight against injustice and inequality, September 18, 2018, represents that women are gaining new spaces towards a global intergenerational demand for changes. White and black, men and women, the youth and the elderly, the movement "MeToo" in the USA and in the western world, women Muslims in La Meca -Saudi Arabia-, "MeToo" Italian version, massive demonstrations in Spain, prove this. For some, this move is the last stage -after May 1968- towards real social changes: "if society does not want to give what owed, women will get it out and will not pay for", or as some authors sustain "if men do not move, women do not need men". Women represent half of the population, and time is over to feel guilty, no more gender and sexual violence, no rape, enough of feeling badly or to suffer in silence. Women survive in difficult situations, and society exonerates women.

Not many years ago, men did not contribute much at home; equality reduced to the discursive level, there was no much equivalence in real practices. During the 1970`s, left thinking demanded male chauvinistic violence, and feminism, was considered a tiny move, not serious. In 2018, feminist movements are pushing to changes without violence. It is enough about being politically correct, to talk about proper things, and to express oneself clearly, is opportune, and to feel ashamed about making this clear, is over. Do not be afraid about expressing, it is the time to be clear (Despentes, 2017), even if some claims are difficult to understand, say: against the poor, the rich, the migrants, the victims, the middling's, the Muslims, the Jews. Clarity justifies a new deal for feminism against old-fashioned 
patriarchy, sexual violence and pornography.

In 2018, everything delays, the age to study, to marry, to reproduce, to die, and everything jumps quickly. However, the equitable redistribution of wealth takes longer than to having access to vote, or to civil equality. In the 21 st century, social class and poverty overcome ethnic factors to convey to inequality, the ghettos and marginalized areas, the pockets of poverty in the cities, and/or unemployment ratios for the deprived. There is clear evidence about. The so-called "American dream" based in racial injustice, has expanded to different groups, segregation has expanded in schools, in the social services, in life. In addition, while the marginalized are accused of being idle, lazy, spendthrifts, blind drank, and others, women are the losers, while money destined to campaigns against poverty, and social and educational assistance, drifts to penalty systems, security programs, policy intervention, or for a wall in the border of Mexico. There was a time when many humans had access to good jobs, but good jobs are less and accessible for just a few, while the index of poverty has increased. And this is something that we are going to deal with, in this paper, referencing Nursing as a "feminine gender profession".

\section{Industrial Evolution and Social Development}

Medieval and contemporary organization of society supported on farmers, artisans, soldiers, religious servers, and others, integrated a model of society that transferred the mechanisms of protection of family life. It was a model of families which sacrificed excluding women from social production and directing them to domestic tasks. The consequence was the differentiation between the public scope, as an option socially well considered, and the private one, as an option less meritorious. Men had to work outside, being paid for their role in the process of transforming primary products into more salable goods. They had no control over production processes, but had a salary in return, and discipline, hierarchy and economic power governed their lives. The earned salary was taken home to the sacrificed family who was to fulfill the remaining tasks of production (Zufiaurre, 1999: p.154). Women received money from men to keep the house, prepare food and clothing, and to care for the children. Thenceforth, the outcome implied male control, domination and possession.

Long-term workers, men and women were required in the early industrial. Consequently, women -who hitherto had been at the service of men for domestic and cleaning tasks: in the private scope of life in an agrarian society, gained more relevance. Women could work in the brand new industrial sphere, gain a salary and get a certain independence. However, this did not certainly mean women could choose industrial work instead of housekeeping. The destiny was to combine both, private and public spaces of life and development. There was a need of an institution to keep and guard (Hamilton, 1996). Elementary school took its path, and in the course of time, steam power was replaced by electricity. What followed: more sophisticated models of production, alterations in workers` and working purposes, and the reorganization of, small industries and/or workshops as medium work spaces. Contemporaneously, industrial areas were surrounded by urban spaces, large families switched to smaller nuclear ones, and easy access to transport and to services, was complemented.

The second stage in industrial revolution - electricity based or services society- allowed women partial freedom since there were fewer housekeeping demands and better access to services. Schooling became more usual, and changed its aims following the demands for more qualifications. In addition, children could perform new identities for a future productive life. Women gained their space for guardianship and care in professions bounded to social and health services, and in educational early stages, what is, professional roles related to assistance with less social value and motherhood functions. Feminine activities with lower status moved in the space of public and private spheres. Moreover, this was the context where the capabilities of women were best valued. After world wars, the stage of postwar consensus (Jones, 1983), "the golden ages" in France, pushed quality of life and social participation to increase. Women gained a little more freedom in family life and in their workspaces, if there were, as they had to combine house and motherhood responsibilities. The development of household appliances reduced the time spent on domestic tasks and, in the "service sector", there were work options to encourage women wider participation in society.

For 1970 's, economic and industrial evolution required people prepared to take part into a flexible labour market, in which "feminine" qualities and abilities were beginning to be considered important. The areas of health, the social services, and education, developed as segregated goods to consume, building a strange package, public service, mass assistance and quality standards. Thus, the most obvious space for women's professional expansion, was in the "service sector", in "social welfare services", in what we term "feminine professions" as nurses, teachers, social workers, secretaries, or similar jobs. This professional base, however, involves contradictory feelings and challenges for women related to their poor self-esteem, their scarce social role, and the devalued professional perception of 
themselves, or their socially diminished level of satisfaction at work.

By the last quarter of the 20th century, the illusion of a full employment market in a services society ended. Meanwhile, the development of technology in the models of production and commercialization with the generalization of computing, was to open the way towards a further stage in evolution. Computing sciences, developed in the military and space industries, transferred to other fields of development, production and education. The coincidence of industrial and economic crisis, together with structural unemployment, and the increasing of part-time work, played a part in a more stratified social and economic jump. Internationalization and globalization of economies and the transforming rules of competition, forced a great restructuring in the processes of production and distribution to delegate professional responsibilities. The original Ford-Taylorist model, did not meet the challenge of flexible productivity, reduction of labour and capital costs. Moreover, a new model of management and production: the Toyota model (Coriat, 1994: p. 20-23), opened the way to the revolution of quality, new work spaces and new tasks for 1990`s (Murgatroyd \& Morgan, 1993: p. 44). What comes next, is a fourth stage in industrial revolution: the age of information technologies.

\section{Feminine Professions: Nurses as Professionals of Care}

Nursing and Care Keepers (and Infant teachers as detailed in a paper, Zufiaurre \& Perez de Villarreal, -2014), are "feminine professions". They are, and have been, in the hands of women because of western world social stratification of labour (Apple, 1986) which supports that assisting, rearing and acting, as mothers do, are and should be a substantial part of the professional world for women. However, up in the 21st century, society and evolution have changed while, in parallel, more pressures towards working circumstances and working conditions, open. Can we think that feminine professions are devalued because just (or most: $98 \%$ in Navarra in 1996, and over 95\% again in 2006 and 2016) women get access to them? When a profession is historically devalued, is it because men do not have access - or do not want to have- to one, or another, professional field?. Can we situate these questioning just in a professional scenery? Yet "gender research", has not inquired much about this, and there is no serious research about this topic. Caring sick humans, and/or humans in need of assistance -at the public sphere- and motherhood as care keeper -at the private sphere-, keep clear similarities. However, to build up relationships, taking initiatives, or confronting new challenges, are deep issues to think once and again.

Nevertheless, what certain, is that researching about "feminine professions" cannot be developed widely if we leave aside real happenings. Nurses work, as health care keepers, while health research is in the hands of powerful international trusts and pharmaceutical companies (similarly to childhood education teachers when Childhood educational organization and research, or infants rearing and protecting, cannot be controlled by them (Zufiaurre \& Pérez de Villarreal, 2014). Being this the context, to research on "feminine professions" cannot be done without analyzing, in parallel, why this work, and these professions, are important as an inversion in human and social capital for progress and for democratic development, and also, and at the same time, why these are important to prepare future healthy citizens of the world. In this paper, we refer to Nurses as "valued - devalued" health professionals, or health servers at the top down of the health ladder. We refer to the dimensions of care as integrated in societies modeled by relations of dominion and dominance, and we refer to Nursing for historical and contemporary reasons. It is true that professions are not stereotyped, not fixed, neither gender heritage, that they create along the time and situations can reverse, but to contribute to changes in society, they are to be reputable.

In those situations in which one or another movement gets an important symbolic power, apparently successful for one or another circumstance, we should remember that this symbolic power can be easy to get, more difficult to use, and easy to lose. Research on "gendered health care", has ran a path forward, but if practitioners and professionals do not find a joint space, if theory is not accompanied by guided practices, research on "gender and health" will not be successful. That is why it will always be relevant to clarify the state of the art in "gender studies" in order to dismantle the modern gendered biased order. However, this is not enough. When changing attitudes related to discrimination sustained on gender differences, practical clarifications and realities are always present. Research on, or related to practice, leads to better results than reflections on issues, which are important, but difficult to grasp. Knowledge and theory are important, but consciousness and action get further on (Weiner, 2012, p.4).

Researching about Health professionals, Care Keepers and Educators, as gendered professions, has taken a different path from investigating ways in which health, social services and schools, minimize gender inequality to become theoretical and empirical fields of research. In times of crisis, however, the disparities between men and women continue to exist, and even increase. That is why, to reference the paths towards equality in male and/or feminine professions, we are forced to weigh up salaries, social esteem, labor compromises, prestige, and others. In addition, 
this is especially important when dealing with men and women sharing public and private spheres of life. In gendered professions, the role of women as nurses, teachers and care keepers, or put it otherwise, professions dealing with human's rearing and educating (Zufiaurre, Pellejero, 2000), demands a new balancing pole in time of a technological revolution.

\section{Feminisms: Research and Practice}

Research on feminism, and/or academic feminism, is mostly concentrated today on big issues related to violence, inequality, and other similar aspects (Moran, 2011), by using sociological research, cultural studies, and /or social sciences related issues. Feminism research, as such, does not engage much with the everyday life of ordinary women and their concerns. To re-turn it to the world of practitioners, to everyday issues and concerns, and to engage in the struggle for equality, is certainly a challenge. The concept of gender (rather than sex), emphasizes that men and women, girls and boys, are socially and culturally produced, rather than shaped by specific biological differences. Following Connell (1987), gender difference (in terms, for instance, of individual behavior, attitudes, material conditions), femininities and masculinities, are structurally created and refined at different levels and in different contexts (e.g. global, national, institutional, individual).

"Gender research" is a flourishing field of research (Zufiaurre, Weiner, Pellejero, 2010) which pushes to improvement and to social changes from gender perspectives, can move otherwise, and can move backwards. Any movement with aspirations of change is to be rooted. To reduce the gap between theorizing and practical issues, activism is most important (Maguire, 2006), but positive intervention is necessary. What should be over, in this sense, are the discriminatory practices and stereotyped views of girls and women tied to their biology, nature and the private sphere of the home and boys and men to abstract thinking and the public sphere of paid work, industry and politics.

In order to identify "the formal and informal processes of power and policy that affect women's and men's advancement and full development" (Marshall, 1997: p.2-3), it is important to draw on Gender theory and Feminist critical policy analysis. How policies aim at increasing gender equality is affected by ideology. Governmental and supranational ideologies (Codd, 1995), their practical approaches and the resulting forms of governance, for instance, the impact on the manner and form in which equity and gender programs are initiated and sustained with progressive politicians, sometimes more and sometimes less influential, as regards gender policy-making than women's groups, or other feminist activists. Moreover, what becomes important is to "dismantle conventional and limiting definitions of policy analysis" (Marshall, 1997: p.3) which omit the influence of wider cultural factors such as gender, ethnicity, or social class, on how policy defines and in whose interests.

Following our analytical gendered framework in times of neoliberalism, what becomes important is to draw on the shift in understanding about how education and health are governed and managed in periods of deregulation and performance management, also evident in the shift in terminology from government to governance (Durose and Gains, 2007), and from ideology to discourse (Foucault, 1972; MacLure, 2003). What used to be the preserve of the state is now "distributed or decentralised to a range of actors and agencies, including, in some cases, private companies" (Lindblad, Ozga \& Zambeta, 2002: p.620). Thus, while the purpose of decentralisation is ostensibly to increase citizen involvement in the decisions of the state and to "shrink" the state, the main consequence has been an increase in managerialism and more responsibility accruing to the new self-managing citizens. Thus, power from the centre replaces by reliance on "softer" management practices, such as target setting and performing to objectives set by the centre and self-evaluation, what evidences the delegation of responsibilities from the professionals. Moreover, the individual becomes the person responsible for maintaining the level of quality of service.

This has rendered the relationship between policy and practice, control, regulation and autonomy, highly unstable and fluid. The processes of governance are gendered (Murray and Maguire, 2007: p.289). Thus, the extent to which social actors such as feminists are able to intervene in such apparently open systems of rulemaking, monitoring and implementation, is questionable. Stearns (2003) shows that feminists have sought to influence the decision-making processes at the supranational level, and have to some extent been successful in penetrating governance, for example, in gaining the acceptance of the mainstreaming of gender issues in organizations such as the United Nations and the European Union. However, Stearns (ibid), notes that because of womens' general lack of power in the political sphere, many of such gains can be easily reversed when resources become scarce.

We can make a difference at this point between the symbolic and the material power (Mazur, 1996), to differentiate between statements, interpretations in practice and outcomes. "Symbolic" refers to policies lacking defined measures: what to do about health care when there is no budget at disposal, whereas "material" policies contain measures aimed at policy implementation and change. The aspirations emanating from policy legislation, and their visible discursive 
and material implications, are different. In addition, the equality of all towards the access to health services is to be aligned with the dignity of the professionals who are responsible about caring. In this paper, we make a difference between policy statements per se and their interpretation in practice, and outcomes, in one or another space.

No feminist analysis can at this point be neutral. Gender is to be used as a lens through which to conceptualize the policy apparatus that maintains and breeds male oriented systems of perceptions about reality. For one or another reason, women as professionals, work twice, paid and unpaid, care is not socially considered, and women abilities about sharing and cooperating in their contribution to the work market, are not especially valued. The work market is biased from gender perspectives, women salaries are lower, and this is even worst in difficult situations, and in times of crisis. Penetrating governance from gender perspectives can be gaining acceptance, but policy advances can be easily reversed.

\section{A Research About Caring: What Nurses Feel About Their Profession}

To analyse how Nurses feel about their responsibilities at work, we report on a research initially developed from 1993 to 1996, with a continuity each ten years to validate the information through round tables and statistical data, first in 2006, and next in 2016. The research develops in Navarra, a northern Community in Spain (population, 643.234 inhabitants). It extends to nurses, infant school teachers, and social workers. In this paper, we explore how Nurses think and feel about themselves and about their professional role. The research was first organized, in 1996, around a questionnaire plus interview sessions that referenced 154 items, with 303 Nurses, from a global of 1630. In 2006 , these were 1816, and in 2016, 1718. The selection of the sampling is done at random; the level of reliance is $95 \%$, the estimation of precision 3\% and the foresight of results 10\%. The aim has been to analyse the Professional perception, personal esteem, and social role, level of satisfaction at work, personal and professional achievements, of Nurses, infant school teachers and social workers.

The results suggest that «feminine professions » involve contradictory perceptions and feelings for women. Women appear professionally satisfied, but they also maintain that they are not properly considered as professionals; they are not feeling socially valued, and therefore, suffer of lack of esteem, depression and inferiority. Contradictions between their private and public domains give women a sense of being in charge of taking care, instead of being considered primarily as professionals. A common feature to detail is their intrinsic vocational commitment, which seems to be used as an emotional mattress for society. All at the same time, the social recognition of women 's professional roles does not match the social responsibility they have. Moreover, women find it difficult to separate -emotionally and existentially- the idea of professional and non-professional tasks.

Women nurses continue to combine professional and domestic responsibilities. This leads to expressions of dissatisfaction about neither being efficient enough in their work nor in their private activities. The salary they get for their paid work tends to be low and is seen as complementary to the male family wage. Casually at this point, in 2006, and even more in 2016, when comparing salaries with part time workers, service sectors, and entrepreneurs, Nurses assume they are better paid, but they sustain that what gets worst each time, is to have access to a regular secure job. For Nurses, their social responsibilities and their health care salaries should balance better. There is an evidenced paradox, as they perceive, they suffer of poor social and welfare development available engaged, as they are, in professional welfare activities for the society. Welfare professionals lack self-esteem because they feel a kind of separation between vocation, personal and professional experience, on the one hand, and anxiety, stress, depression, physical and mental fatigue, social disinterest and few expectations for the future, on the other. Poor work conditions, not having options for promotion unless they study Medicine (a differentiated curricular option) while working.

For these women, the poor work conditions and their domestic demands have few compensations. In their "inner self", in relation to labour compromises, however, women Nurses report satisfaction about being professionally active and being useful: personal life quality and some economic value. In relation to personal and social effects, some negative features arise. To mention, emotional dependence - independence relationships with their family and labour realities, lack of free time, specific professional risks, a secondary status in the chain of health services, not arriving in time to fulfil expectations, and several forms of dissociation between beliefs and reality in the mix relationships between domestic and labour activities, etc.

\subsection{Research Hypothesis}

Five different claims are examined in our research about how Nurses feel:

- Nursing is a "feminine profession", and it is mostly in charge of women. 
- There is a meaningful connection between physical and psychic disorders associated to the development of these feminine professions.

- The access of women to work in "feminine professions", such as Nursing, favours in a significant way women`s quality of life and material prosperity.

- The access of women to work in "feminine professions", does not favour in a significant way women's quality of life in respect to cultural and personal balance, development and self-esteem.

- The quality of the services rendered by women working in "feminine professions", such as Nursing, does not appear socially valued in concordance to their contribution to increase "quality of life" of others in society.

\subsection{Some Research Outcomes}

5.2.1 From our research about how Nurses feel about their profession, what becomes clear, is that most (94\% in 1996, $92 \%$ 2006, and $95 \%$ in 2016) of the Nurses in Navarra, working on health services, made a real vocational decision when they decided to train as Nurses. They also report maintaining a professional interest in taking part in continuous training (96\% in 1996, 95\% in 2006, and 97\% in 2016). To get prepared for assuming more responsibilities, and consequently improving salary, Nurses need to start studying again to become doctors. Continuous training resumes to new techniques and treatments. The time these Nurses spend in full time work, as Nurses report is $52 \%, 8$ to 17 years; $21 \%, 18$ to 30 years; and just $1 \%$, more than 30 years, in 1996 . In 2006 , this hardly changes $54 \%, 21 \%$ and $1 \%$, and in $2016,53 \%, 24 \%$ and $1 \%$, respectively.

5.2.2 Women Nurses are vocationally satisfied, but have a sense of inferiority as they feel that they are not socially valued as professionals. They are happy at work and want to do it well but, as Nurses sustain, the doctors and the Health system do not count much on their expertise. Nurses exhibit a social consciousness about their professional role, and thus, $69 \%$ feel stressed, edgy and anxious (73\% in 2006, and 77\% in 2016). They feel they cannot manage to do all they want to do, and related to options for promotion, women Nurses feel they do not have much to do, and compared with men professionals even less ( $28 \%$ sustain men and women Nurses have equal options, $61 \%$ different, in 1996; in $2006,24 \%$ and $67 \%$; and in $2016,23 \%$ and $69 \%$ ).

5.2.3. Related to a certain external perception that Nursing work keeps similarities to the work of the mothers, easy for women, $79 \%$ and $68 \%$ of the Nurses mention that they do not feel better prepared because they are women, or because their work keeps similarities with the work of mother's. The majority of the Nurses: $71 \%$, do not assume that they are more at ease, more patient, or have a wider range of options when caring citizens health. For $91 \%$ in 1996, 89\% in 2006, and $88 \%$ in 2016 , men can have the same discipline at work; similar patience: $71 \%$ in $1996,69 \%$ in 2006 , and $68 \%$ in 2016. Their low social esteem, seems not to depend of the importance of caring the health and assisting patients $(81 \%$ in 1996, 85\% and $84 \%$ in 2006 and 2016), but because of the techniques and routine care they are to develop.

5.2.4 Women Nurses have a perception that they do not have so many sick leaves as they should have as a consequence of their labour conditions, requirements, stress, anxiety, and others. In 1996, 29\% report they have stopped work for a while the last year, and 34\% report they should stop but did not. In 2006, 26\% report they had, 38\% should have stopped; in 2016, 25\% and 39\% respectively. In 1996, 69\% mention stress as a cause of sick leave, $65 \%$ in 2006 and $66 \%$ respectively. About professional health compromises at work, in 1996, $42 \%$ report their compromise is high, and $50 \%$ low; in 2006, $40 \%$ high, and 54\% low, while in 2016, 41\% high, and 51\% low. Their perception about personal health is, in $1996,82 \%$ good, $78 \%$ in 2006 , and $76 \%$ in 2016 . The problems mentioned were related to *breathing: $11 \%$, *muscular skeletal: $37 \%$, *limitation in activity: 26\%, *nervous system: 16\%, *relief, relax and sleep: 31\%, in 1996. In 2006: $13 \%, 38 \%, 25 \%, 18 \%, 33 \%$, respectively; and in 2016: $12 \%, 39 \%, 28 \%, 18 \%, 35 \%$. About physic and psychic professional risks, in 1996: for $89 \%$ there are, $86 \%$ and $89 \%$ in 2006, and 2016 respectively.

5.2.5 For $96 \%$ of the Nurses, professional expertise improves their capacity to take decisions: *problem solving: $97 \%$, *feeling of security: $86 \%$, *tolerance: $73 \%$, *perceive stress: $86 \%$, *optimism: 50\%, *personal coherence: $65 \%$, *level of interest: $72 \%$, in 1996: In 2006, and respectively: $95 \%, 97 \%, 84 \%, 71 \%, 87 \%, 54 \%, 63 \%, 71 \%$; and in 2016: $98 \%$, $94 \%, 82 \%, 70 \%, 81 \%, 52 \%, 61 \%, 69 \%$. However, Nurses perceive that the social recognition associated to this is low. And the reasons they mention: the topics associated as predestined duty to women, and/or associated to the work, simple charges of care, take information, deliver the medicines, cleaning, etc. As they perceive, the social recognition, the social consciousness and the social image of Nurses, is low compared with the doctors and intermediate professionals of health. At this point, new efforts and new measures are necessary to improve the working conditions and the quality of work in health and social services professions.

5.2.6 Women Nurses report that they share, in a way, domestic work with their partners. But following their answers to our questionnaire, interviews and round tables, we point to the different aspects, no evidence is shown. In 1996, 58\% 
( $62 \%$ in 2006 , and $64 \%$ in 2016$)$ sustain to share domestic work in the family. The same year, $1996,22 \%$ report they are in overall charge ( $25 \%$ in 2006 , and $28 \%$ in 2016). In $1996,20 \%$ have domestic help $(17 \%$ in 2006 , and $16 \%$ in 2016). This information points to a certain average of women nurses who do not share family duties and a certain average of women who have no option to appoint domestic help or, if it is the case, to have external domestic help without a contract. Referencing different aspects to share, in 1996, 73\% of the Nurses take charge about cooking, $68 \%$ ironing, $68 \%$ cleaning, $79 \%$ shopping, $73 \%$ taking children to college, $85 \%$ taking care of the elderly. Curiously in the items 7 and 8 , just $9 \%$ accompanying relatives to the doctor, and $8 \%$, taking care of sick people in the family. In 2006, and in this order, they refer: $64 \%, 76 \%, 77 \%, 74 \%, 69 \%, 86 \%$, and $51 \%$ and $54 \%$ in items 7 and 8 . In 2016 , and in the same order, what referred is $68 \%, 78 \%, 73 \%, 70 \%, 69 \%, 88 \%$, and $58 \%$, and $61 \%$ in items 7 and 8 .

It is clear that while around $45 \%-50 \%$ of the Nurses sustain that they share domestic duties, when pointing to specific items their answers do not confirm this. In addition, the strange answers to the items 7 and 8, a possible explanation comes from how women Nurses feel about not being able to arrive in time to do what they feel and want to do. There is clear evidence that when there is a nurse in a nuclear family, she is the first one to assist the sick, the elderly, or accompanying to the doctor, etc. Consequently, to make plans about sharing domestic tasks, needs of great efforts to share social and family responsibilities, to promote consciousness about, and specifically, to empower women, and specially women compromised in "feminine professions" when the topics about special works for women mothers are too settled. In 1996, 72\% (even more in 2006, and 2016) appointed that more than $35 \%$ do not share a family conventional structure. Our Nurses reported that they did not have free time to do what they had to do, or they would like to do.

5.2.7 About the salaries women get for their professional work, in 1996, 38\% consider is good enough, but 53\% not enough. In 2006 and 2016, less than 30\% think it is good enough and more than 65\% claim it is not enough. In 1996, for $47 \%$ of the women, their salary is complementary in their families and for 18\% the only one; in 2006 and 2016, about $40 \%$ say it is complementary, and about $25 \%$, unique salary. On the other hand, the salary they get contributes to buy food, clothes, health, but it is never enough to buy a car or for housing needs.

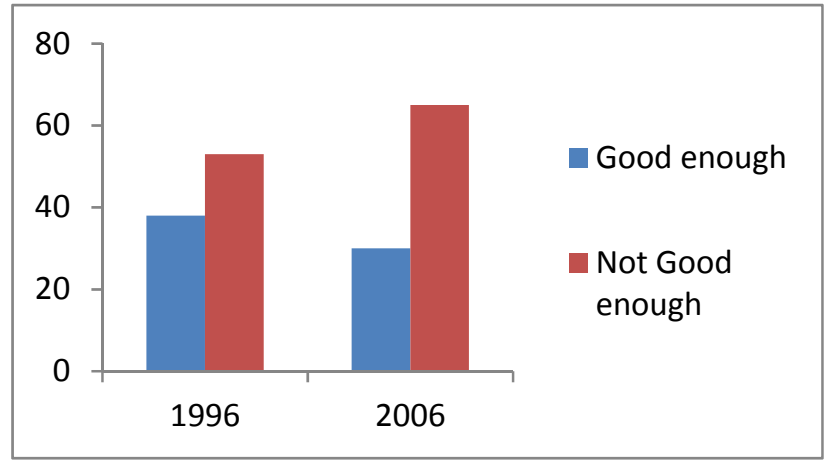

Table 1a. Salary (Good or Not good enough)

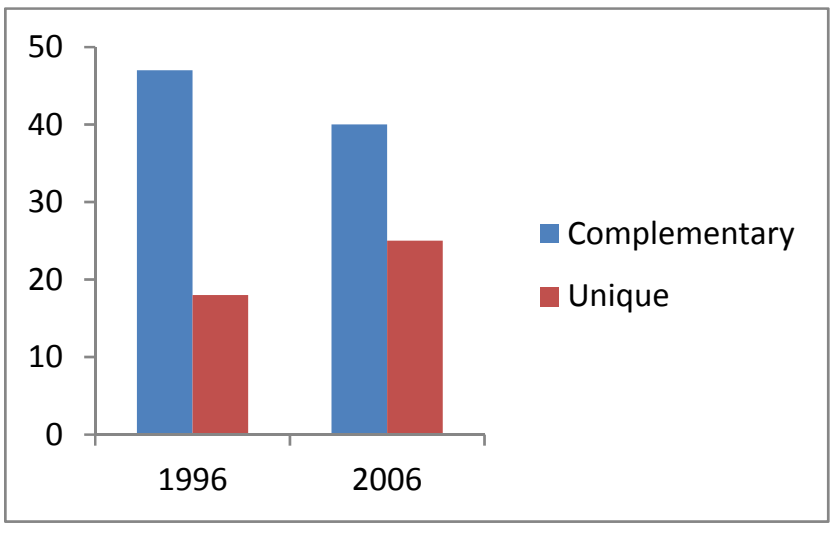

Table 1b. Salary (Complementary or Unique) 


\section{Concluding Remarks}

In 2018, when women openly claim for their rights, in developed societies, policy equal rights for men and women are guaranteed and women professional abilities are equally valued. There is equal access for men and women to education and civic development, but because of technological development new pressures have emerged. Neoliberal redistribution of responsibilities, forces to adjust costs for rentability and competitivity, while economic recession reduces job opportunities and spaces to affect specifically the weakest sectors of our societies. To be well prepared and educated, or to have the rights, does not mean that we all have the same opportunities. Everything is possible today, but changes get forward with difficulties while insecurity limits development and leads to a crisis in affective, economic, and formal standards of life.

The Second stage in industrial revolution, which followed to postwar consensus (Jones, 1983), pushed women to gain a certain public space in the "golden era" by being productive and efficient workers. Expansion and security of work, extension and standardization of schools, social advancement, over-production, traced the path to social and economic development. Women gained the right to have their own salaries once they accessed to the work market. Meanwhile, domestic tasks reduced because of changes in family life. 1960`s and 1970`s traced an opportune context for a new contract towards sharing domestic tasks once welfare becomes important to provide a balance to economic development. Information technology and robotics have reduced productive work opportunities, but there are work options at "service" sectors: health, education, social services. These professional tasks, are not only work options for women, but crucial factors to progress and for economic development. And in our postmodern world, inclusive perspectives about developing human rights and human development, should get in the agenda of inter and supra national organizations for co-participation and for personal and social development.

In our increasingly individualistic and competitive societies, welfare state premises to open society to services and social progress are questioned and constructive collaboration has diminished. In a new stage of development in which new compensatory strategies are needed to challenge the globalization of economic production and distribution, we also need to develop new policies around the reduction of work times, work sharing, social salary, etc. And for this new organization, women need to find their space in both the public and the private spheres of life. It is at this point that Nursing, and other "feminine professions", need to find a new way ahead, not as a complementary service to society, in both the public and the private, but as an essential contribution to progress and evolution, which gets far away from topics and limitations of modern stratified societies.

Technologies open a space for work flexibility, and timetable organization that could help to create a new social contract (Lewin \& Rumberger, 1989). This pushes to reconsider the welfare professions -Nurses, and other "feminine professions" to provide a social welfare service to society in order to contribute to the improvement of quality of life.

\section{References}

Apple, M. (1986). Teachers and Texts: A politic economy of class and gender relations in Education. London, Routledge and Kegan Paul.

Codd, J. (1995). Contractualism, contestability and choice: Capturing the language of educational reform in New Zealand. In J. Kenway (Ed.), Marketing Education: Some critical issues. Geelong. Deakin Press. 87-104

Connell, R.W. (1987). Gender and power: Society, the Person and Sexual Politics. Stanford University Press.

Coriat, B. (1994, 2nd Ed.). Pensar al revés: Trabajo y Organización en la empresa japonesa. (Thinking otherwise: Work and Organization in Japanese enterprises). Madrid: Siglo XXI.

Despentes, V. (2017). Vernom Subutex. Madrid: Literatura Random House.

Despentes, V. (2017, 3rd. Ed.). Teoría King Kong (King Kong Theory). Madrid: Literatura Random House.

Durose, C., \& Gains, F. (1995). Engendering the machinery of governance. In C. Annesley, F. Gains and K. Rummery (Eds.), Women and New Labour: Engendering politics and policy? Bristol: The Policy Press, 93-114

Foucault, M. (1972). Archeology of Knowledge. New York: Pantheon.

Hamilton, D. (1996). La transformación de la educación en el tiempo. Madrid, Trillas (English Ed. Learning about education: An unfinished curriculum, Buckingham, Open University Press)

Jones, K. (1983). Beyond Progressive Education. London, Macmillan. https://doi.org/10.1007/978-1-349-17068-5

Lewin, H., \& Rumberger, R.W. (1989). Educación, trabajo y empleo en los países desarrollados. Desafíos de futuro. 
(Education, work and employment in developed countries. Challenges for the future). Perpectivas, 19(2), 221-242.

Lindbald, S., Ozga, J., \& Zambeta, E. (2002). Changing forms of Governance in Europe. European Educational Research Journal, 1(4), 615-624. https://doi.org/10.2304/eerj.2002.1.4.1

MacLure, M. (2003). Discourse in Educational and Social Research. Buckingham: Open University Press.

Maguire, P. (2006). Uneven Ground.: Feminisms and Action Research. In P. Reason \& H. Bradbury, (Eds.), Handbook of Action Research (59-69), London, Sage.

Marshall, C. (1997). Dismantling and Reconstructing Policy Analysis. In Catherine Marshall (Ed.), Feminist Critical Policy Analysis: A perspective from Primary and Secondary Schooling. London: falmer Press, 1-40.

Mazur, A. (1996). Gender Bias and the State: Symbolic Reform of Work in Fifth Republic France. Pittsburg: University of Pittsburgh Press.

Moran, C. (2011). How to be a woman. London: Ebury Press.

Murgatroyd, S., \& Morgan, C. (1993). Total Quality Management and the School. Buckingham: Open University Press.

Murray, J., \& Maguire, M. (2007). Changes and Continuities in Teacher Education: International Perspectives on a Gendered Field. Gender and Education, 19(3), 283-296. https://doi.org/10.1080/09540250701295437

Stearns, J. (2003). Global Governance: A Feminist Perspective. In D. Held \& A. McGrew (Eds.), Governing Globalization: Power, Authority and global Governance. Cambridge: Polity Press, 87-108.

Weiner, G. (2012). A dangerous Addiction: Theory, Feminism and Education. Working Paper, Umea \& Sussex Universities.

Zufiaurre, B. (1999). Comprehensive Polyvalent schooling: Options for a Technological future. Pedagogy, Culture and Society, 7(1), 153-164. https://doi.org/10.1080/14681369900200046

Zufiaurre, B., \& Pellejero, M.L. (2000). Women Infant school teachers in Spain: How does society and how do they consider their professional role?. Pedagogy, Culture and Society, 8(2), 207-218. https://doi.org/10.1080/14681360000200092

Zufiaurre, B., \& Perez de Villarreal, M. (2014). Women Infant school teachers in Spain: How does society and how do they consider their professional role?. Journal of Education and Training, 1(2), 31-47. https://doi.org/10.5296/jet.v1i2.5163

Zufiaurre, B., Weiner, G., \& Pellejero, M.L. (2010). Gender Equality and Education in Spain: Ideology and Governance. Education Inquiry, 1(4), 399-414. https://doi.org/10.3402/edui.v1i4.21953 